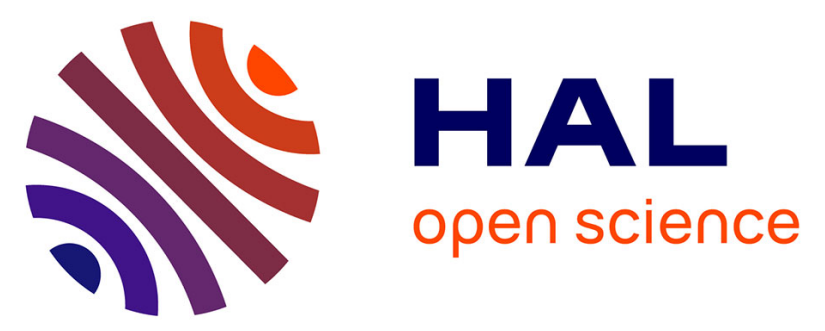

\title{
Multi-step functionalization procedure for fabrication of vertically aligned mesoporous silica thin films with metal-containing molecules localized at the pores bottom
}

Łukasz Laskowski, Magdalena Laskowska, Mateusz Dulski, Maciej Zubko, Jerzy Jelonkiewicz, Marcin Perzanowski, Neus Vilà, Alain Walcarius

\section{To cite this version:}

Łukasz Laskowski, Magdalena Laskowska, Mateusz Dulski, Maciej Zubko, Jerzy Jelonkiewicz, et al.. Multi-step functionalization procedure for fabrication of vertically aligned mesoporous silica thin films with metal-containing molecules localized at the pores bottom. Microporous and Mesoporous Materials, 2019, 274, pp.356-362. 10.1016/j.micromeso.2018.09.008 . hal-01941800

\section{HAL Id: hal-01941800 \\ https://hal.univ-lorraine.fr/hal-01941800}

Submitted on 26 Nov 2020

HAL is a multi-disciplinary open access archive for the deposit and dissemination of scientific research documents, whether they are published or not. The documents may come from teaching and research institutions in France or abroad, or from public or private research centers.
L'archive ouverte pluridisciplinaire HAL, est destinée au dépôt et à la diffusion de documents scientifiques de niveau recherche, publiés ou non, émanant des établissements d'enseignement et de recherche français ou étrangers, des laboratoires publics ou privés. 


\title{
Multi-step functionalization procedure for fabrication of vertically aligned mesoporous silica thin films with metal-containing molecules localized at the pores bottom
}

\author{
Łukasz Laskowski ${ }^{\mathrm{a}}$, Magdalena Laskowska ${ }^{\mathrm{a}, *}$, Mateusz Dulski ${ }^{\mathrm{b}}$, Maciej \\ Zubko $^{\mathrm{b}}$, Jerzy Jelonkiewicz ${ }^{\mathrm{c}}$, Marcin Perzanowski ${ }^{\mathrm{a}}$, Neus Vila ${ }^{\mathrm{d}}$, Alain \\ Walcarius $^{\mathrm{d}}$ \\ ${ }^{a}$ Institute of Nuclear Physics Polish Academy of Sciences, PL-31342 Krakow, Poland \\ ${ }^{b}$ University of Silesia, Faculty of Computer Science and Materials Science, Institute of \\ Materials Science, Silesian Center for Education and Interdisciplinary Research, ul. 75 \\ Putku Piechoty 1A, 41-500 Chorzów, Poland \\ ${ }^{c}$ Czestochowa University of Technology, Department of Microelectronics and \\ Nanotechnology, Al. Armii Krajowej 36, 42-201 Czestochowa, Poland \\ ${ }^{d}$ LCPME 405 rue de Vandoeuvre, 54600 Villers-les-Nancy, France
}

\begin{abstract}
A novel method for fabrication of precisely functionalized nanomaterials was developed. Presented here multi-step functionalization procedure can be applied for vertically-aligned mesoporous silica thin films. As an example, we presented the syntheses of films, precisely functionalized by the propylcopper-phosphonate and the propyl-silver-carbonate groups located exclusively at the pores bottom. Obtained functional materials were characterized by a few physical and chemical techniques: transmission electron microscopy, X-ray scattering, differential pulse voltammetry and infrared spectroscopy supported by the numerical simulations. On this base, we prove the efficiency of the synthesis method. We expect that presented multi-step functionalization procedure can be easily generalized and applied for fabrication of the novel porous silica-based functional materials.
\end{abstract}

Keywords: mesoporous materials, functional materials, functional units

\footnotetext{
*Principal corresponding author

Email address: magdalena.laskowska@ifj.edu.pl (Magdalena Laskowska)
} 
distribution, porous silica, thin layers

\section{Introduction}

Functional materials based on the porous silica matrix and the transition metal-containing active groups have become very attractive architectures due to their unique properties [1]. They can be considered as the compounds possessing particular properties, precisely tailored to the specific functions [2]. These properties are usually a result of a purposely designed molecular structure and carefully elaborated synthesis route. The materials possessing such unique properties have found various applications in electronics [3, 4], energy storage [5], sensing[6], catalysis [7, 8], or even bioactive systems [9]. Especially, the thin films formed by the functional materials are crucial for the implementation in the nanoelectronic $[10,11]$ or optoelectronic systems $[12,13]$ as well as in solar cells $[14,15]$.

The bottom-up approach to nanotechnology [1] has opened a promising way for the fabrication of materials having extremely ordered structure on the molecular level with means of self-assembly method. The properties of such materials are very sensitive to the supramolecular arrangement of the functional units, that determines the molecular polarity and hence all molecular properties [16]. The intermolecular interactions are responsible for cooperative phenomena and for the appearance of new features at the space charge transfer. Thus, the same molecule behaves substantially differently in a different environment or being distributed in a various way in the matrix. This feature can be applied for designing of materials for the use in optoelectronics. The most applicable form of such materials is a thin film. Nevertheless, designing and fabrication of functional thin films with desired features is still a challenging task. Moreover, the synthetic routes are often complicated and the structural characterization can be ambiguous. However, a possibility of the physical properties arrangement to achieve desired functionalities is still worth the effort. Having a proper matrix one can obtain the material tailored for a particular application. However, the condicio sine qua non in this case is fully controllable functional units distribution inside matrix volume. it is difficult but possible to achieve. As we shown in our previous works it is possible to fabricate a precisely functionalized silica-based strongly antimicrobial system, that is safer for the environment than commonly used disinfectant

agents [17], or novel materials for optoelectronic: silica thin films possessing 
tunable nonlinear optical response [18]. In both cases, the key was extremely precise matrices functionalization and control of functional units distribution. All these results prompted us for searching for an even more accurate way for functionalization of nanostructured materials.

In the paper, we propose an innovative approach to a synthesis of completely novel thin film composite material based on the vertically aligned mesoporous silica matrix: the multi-step functionalization procedure. This synthesis route is designed in such a way that each of silica channel contains the metal ions anchored exclusively at the pores bottom.

The method presented here provides an opportunity to achieve the precisely designed molecular structure of the samples. Moreover, this method can be easily generalized to be used for the fabrication of a new, very sophisticated nanomaterials, especially for the use in nanoelectronics devices. In the case of using derivatives of $\mathrm{Mn}_{12}$ molecular magnets, it is possible achieving of the regular layout of bistable magnetic units, that can play the role of a super-dense memory or a basic element of the molecular implementation of artificial neural networks (work in progress). However, in a first step, the functionalization procedure should be presented and thoroughly examined with a series of physical measurements, what we do in this work. The structure of the materials being the subject of this article shows fig. 1.

Unfortunately, considered materials are not easy to investigate because of their very low thickness. So, determination of their molecular structure can be still demanding. Therefore, we propose the investigations set (structural, spectroscopic and electrochemistry methods), that can be applied for very precise determination of the thin film samples molecular structure and also individual functional units configuration.

\section{Materials and methods}

\subsection{Synthesis of vertically aligned mesoporous silica thin films functionalized at the pores bottom}

The multi-step functionalization procedure was designed according to the BOTTOM-UP approach to the nano-engineering. In this method the atoms, during synthesis, create desired structure by themselves, forming vertically aligned thin mesoporous silica layers containing the metal ions exclusively at the bottom of the channels. We prepared thin films containing two type of functional units placed at the pores bottom: 


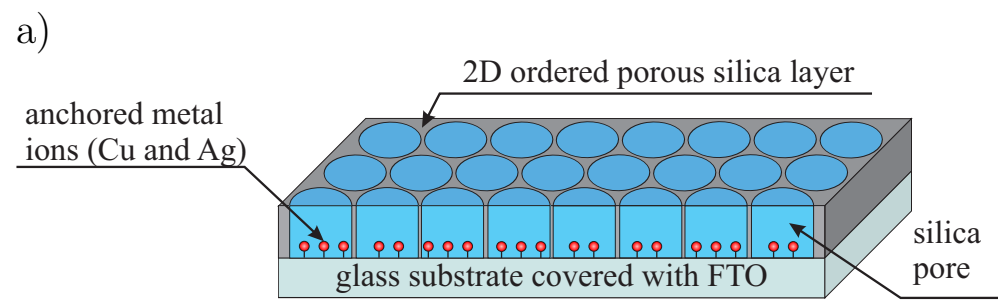

b)

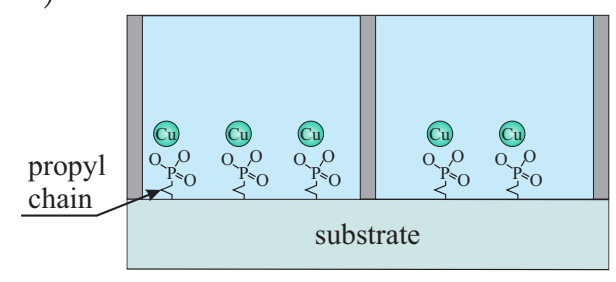

c)

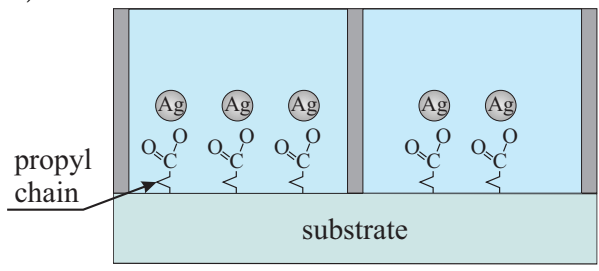

Figure 1: Schematic representation of the ordered porous silica thin layers with vertically aligned pores, containing copper and silver ions bounded at the pores bottom. Prospective view (a) and zoom-in of the species containg copper (b) and silver (c).

- copper ions bounded via propyl phosphonate units (samples hereafter called SIL-POO${ }_{2} \mathrm{Cu}-\mathrm{B}$ )

- silver ions anchored via propyl carbonate units(samples denoted as SIL-COOAg-B)

The fabrication and multi-functionalization of the silica thin films is divided into four main steps which are summarized in fig. 2. In the first step, the substrate - glass covered by the fluoride doped tin oxide layer - is functionalized by the precursors of the anchoring groups. They are the propyl dietyl phosphonate in the case of SIL- $\mathrm{POO}_{2} \mathrm{Cu}-\mathrm{B}$ and the cyanopropyl for SIL-COOAg-B. Next, the pre-functionalized substrates are covered by the layers of highly ordered mesoporous silica thin films with vertically oriented channels. It is done with the help of the electro-assisted self-assembly (EASA) method $[19,20]$. This procedure yields porous silica films with thickness of 80 $\mathrm{nm} \pm 5 \mathrm{~nm}$. After ageing and surfactant removal, the samples are silanated in order to prevent undesirable side-reactions between the surface hydroxyl units and the acidic groups of the anchoring units. Then the samples are hydrolyzed to create destination anchoring units at the pores bottom. Finally, the samples can be activated by metal ions in solution of the metal salts. Thanks to presence of the anchoring units at the pores bottom, the 


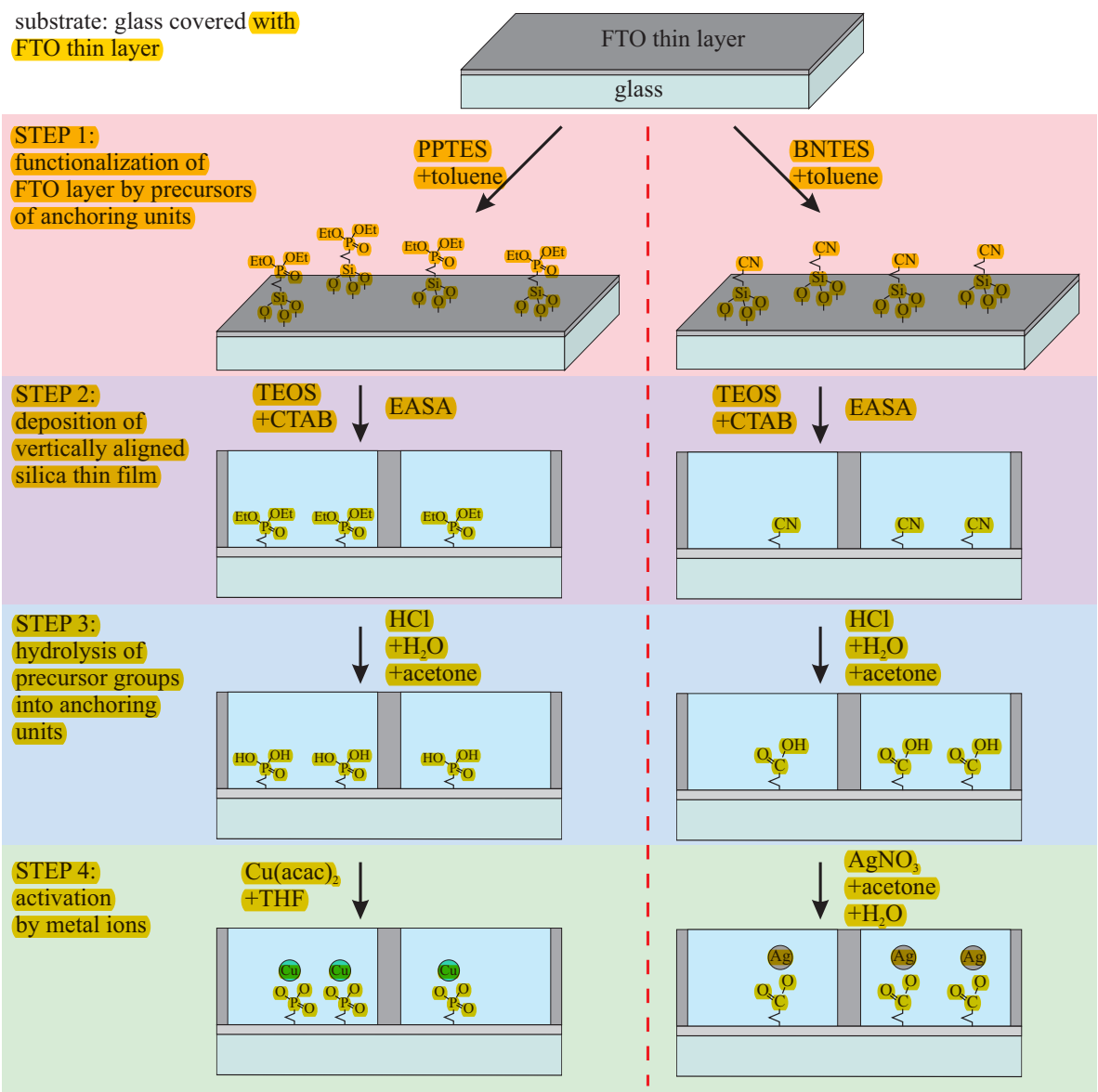

Figure 2: Schematic representation of the synthesis procedure for fabrication of vertically aligned thin mesoporous silica layers containing metal ions at the bottom of channels. Denoting: PPTES - diethylphosphonatepropyl triethoxysilane, BNTES - butylonitrile triethoxysilane, TEOS - tetraethyl orthosilicate, EASA - electro-assisted self-assembly method, THF - tetrahydrofurane, Et - ethyl group. 
metal ions are bonded exclusively in this place, while thorough washing by the solvents removes any salts excesses.

The detailed description of each step can be found in Supporting Informations, section 1 .

\subsection{Characterization methods}

The silica thin films, functionalized at the pores bottom, were characterized by several methods to confirm assumed molecular structure.

The cyclic voltammetry $(\mathrm{CV})$ and the differential pulse anodic stripping voltammetry (DPASV) were carried out by means of the potentiostat/galvanostat SP150 (Biologic) at room temperature in the three-electrode cell where the working electrode was the silica-based composite films on the FTO layer, a platinum wire as the counter electrode, and $\mathrm{Ag} / \mathrm{AgCl}$ was used as the reference electrode.

The TEM imaging was carried out using the FEI Tecnai G2 20 X-TWIN electron microscope, equipped with the emission source LaB6 and the CCD camera FEI Eagle 2K. The TEM images were processed using the Gwyddion software [21].

The XRR patterns of the composite silica-based thin films were collected by means of the X-PERT PRO Panalytical diffractometer operated at $40 \mathrm{kV}$ and $30 \mathrm{~mA}$, in the in-plane geometry (open Eulerian cradle - OEC) with 80 degrees $\psi$ angle. The $C u K \alpha$ radiation of the wavelength $1.541 \AA$ and fixed slits were used. The scattering at the low-angle range of $0.3<2 \theta<8$ was recorded applying 0.03 step size and $240 \mathrm{~s}$ exposure time.

The Fourier transform infrared (FTIR) measurements were performed using the Thermo Scientific Nicolet iS50 FT-IR spectrometer equipped with a standard source and the DTGS Peltier-cooled detector. The spectra of the silica thin films were collected in the $4000-650 \mathrm{~cm}^{-1}$ range using the VeeMAX III with the ATR accessory at the 65 degrees of an incidence angle and the Ge flat plate crystal. All spectra were accumulated with the 16 $\mathrm{cm}^{-1}$ spectral resolution and saved in 200 scans. The water vapor and carbon dioxide were subtracted from each spectrum as well as the baseline correction and the peak fitting was done using the GRAMS Software package.

\subsection{Numerical Simulations}

We carried out numerical simulations in order to identify the vibrational modes correctly (supporting the infrared spectroscopy). 
In the first stage, we designed the numerical model of the investigated materials. The clue of the vibrational analysis was to examine the modes connected with the vibrations of the functional units attached to the FTO layer. Thus, we assumed individual functional units as a model of our material: propyl-copper-phosphonate and propyl-silver-carboxyl attached to a part of FTO. In the light of the fact that the fluoride doped tin oxide vibrational spectra are well known [22] and can be easily measured and subtracted from experimental spectra, we treated the FTO part only as a ballast modifying the functional groups' vibrational modes. For this reason, we use the simplified model of the FTO part: flat $\mathrm{SnO}_{2}$ structure containing only $3 \mathrm{Sn}$ atoms. Fluoride atoms were omitted. The functional groups were designed with no simplification, as elements with unknown vibrational spectra.

Theoretical calculations were carried out in the gas phase using the density functional theory (DFT) calculations [23, 24] available in the Gaussian 09 software package [25]. The geometry of the model molecules was first optimized using the Becke's hybrid exchange and correlated three-parameter [26] with the Lee-Yang-Parr correlation functional (B3LYP) [26-29] as well as the split-valence basis sets $3-21 \mathrm{G}$. Next, the optimized structures were used as input files for further optimization and the vibrational harmonic calculations using the MOLPRO Basis Query def2-TZVP [30, 31], as a fairly accurate basis set, giving reasonable computational time. As a result of the geometry optimization, we had obtained a few conformers for each molecule. The final configurations of the models were selected on the base of the conformational analysis - conformers with the lowest energy had been selected for further considerations. It is worth mentioning, that for the silver-containing model molecule we obtained two probable conformers. As it was shown during further analysis, both conformations of the propyl-silver-carbonate are present in the resulting sample.

The optimized structures were used as the input files for the vibrational harmonic calculations. All structures had positive harmonic vibrations that proves a true energy minimum [25]. Theoretical vibrational frequencies were recalculated using the scale factors of 0.9654 [32] to avoid their inaccurate estimation caused by neglecting the anharmonicity, incomplete incorporation of the electron correlation and the use of the finite basis sets in the theoretical treatment. Due to the perfect correlation between theoretical and experimental spectra and coherence of further interpretation, the choice of the method and the basis set seems to be fully justified.

The assignment of the calculated Raman bands was done on the basis 
of the PED analysis $[33,34]$ and supported by the animation option of the GaussView 5.0 graphical interface for the Gaussian programs [35], useful for a visual presentation of the vibrational modes shape. As far as the PED analysis is concerned, the calculations were carried out in the VEDA software [36]. By combining the results of the visualization with the potential energy distribution (PED) we obtained a very accurate description of the molecular vibrations.

\section{Results and discussion}

\subsection{Structural investigation}

The silica matrices structures are verified in terms of their quality with the help of X-Ray Reflectivity (XRR) and the transmission electron microscopy (TEM).

The XRR patterns, shown in fig. 3, confirm regular 2D hexagonal pores distribution for both samples. It is clearly seen that the XRR spectra, obtained for both samples, are similar, what indirectly confirms repeatability of the EASA method. First broad Bragg reflections, observed at $2 \Theta$, equals about $2.05^{\circ}$ while the second ones, much sharper, are visible at $2 \Theta$ of about $3.30^{\circ}$ for both samples. Their position is typical for the reflections from (100) and (110) planes in the hexagonal structure. For both SIL-POO $2 \mathrm{Cu}-\mathrm{B}$ and SIL-COOAg-B samples, the inter-planar spacings can be calculated as about 4.30 and $2.67 \mathrm{~nm}$ for the $\mathrm{d}_{100}$ and $\mathrm{d}_{110}$ planes respectively. It provides an opportunity to calculate distances between pores centers as a value close to $5.1 \mathrm{~nm}$ (peak (100)) or $5.3 \mathrm{~nm}$ (calculated from the sharper peak of (110), what is more reliable). Detailed values can be seen in fig. 3 .

The TEM microscopy gives the direct visualization of the matrices structures. Obtained samples images along with the results of the 2D autocorrelation function $(\mathrm{ACF})$ [21] can be seen in fig. 4. The TEM observations confirm that investigated samples are well ordered within a framework of the domains. The pores are distributed regularly with the $2 \mathrm{D}$ hexagonal arrangement. The ACF results explicitly confirm that the pores are distributed hexagonally $2 \mathrm{D}$ and the average distance between the pores centers is close to $5.1 \mathrm{~nm}$ for both cases, so very similiar as in the case of X-Ray research.

\subsection{Electrochemistry}

The first evidence of successful functionalization and information about the amount of immobilized metal complexes is delivered by differential pulse 


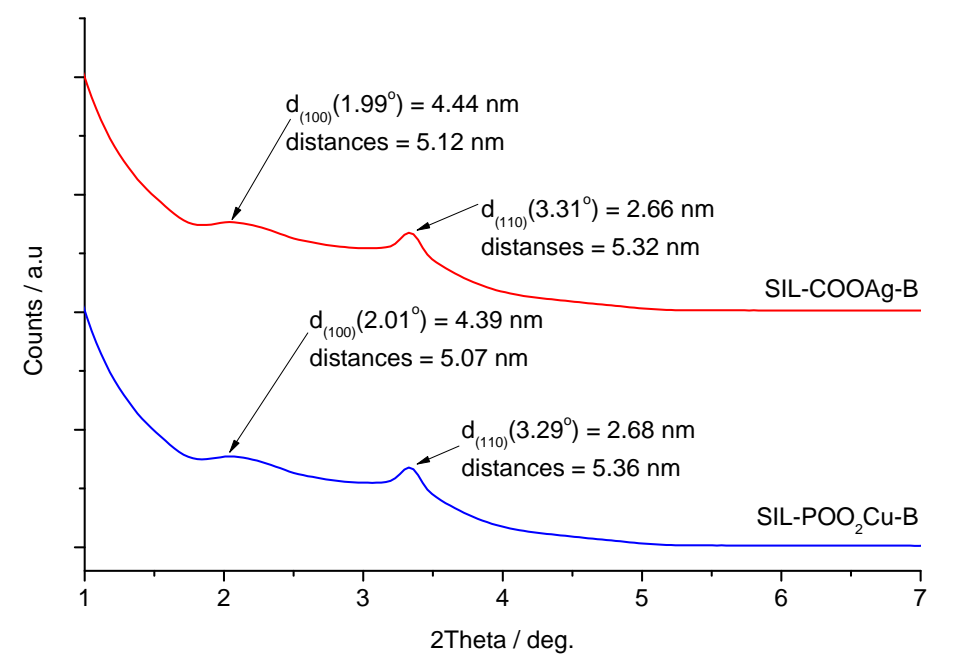

Figure 3: Small angle X-ray reflectivity curve obtained for samples containing copper and silver ions at the pores bottom

anodic stripping voltammetry (DPASV). Such a technique is indeed likely to detect extremely small amounts of metal species via their accumulation by electroreduction and subsequent detection of the metal deposits by anodic stripping in a differential pulse mode [37,38]. This method has been applied here to the relative quantification of copper and silver species attached to phosphonate and carboxylate ligands grafted onto either bare FTO covered glass substrates activated by copper and silver ions (denoted as FTO$\mathrm{POO}_{2} \mathrm{Cu}$ and FTO-COOAg respectively) and the same electrode substrates covered with a mesoporous silica film activated in the same way (proper samples: SIL-POO ${ }_{2} \mathrm{Cu}-\mathrm{B}$ and SIL-COOAg-B) for which metal ions are expected to be localized exclusively at the pores bottom.

Typical DPASV results are depicted in fig. 5 where one can see stripping peaks characteristic of copper and silver, respectively located at $+0.13 \mathrm{~V}$ and $0.30 \mathrm{~V}$. This confirms the presence of bounded copper or silver ions onto the electrode surface and that the amounts of them are larger on bare electrodes than for the same substrates coated with a mesoporous silica film. Actually, one can estimate the relative amounts of metal species by measuring the surface area under the DPASV peaks (see values given in fig. 5). For both copper and silver, the amount of immobilized complexes in the case of the film modified electrodes (SIL-POO ${ }_{2} \mathrm{Cu}-\mathrm{B}$ and SIL-COOAg-B) was equal 
a)

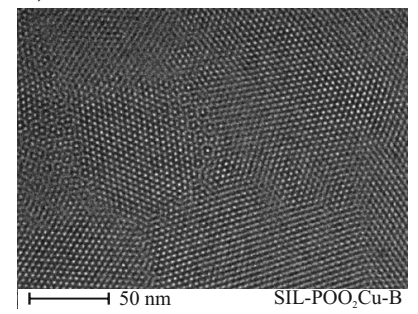

c)

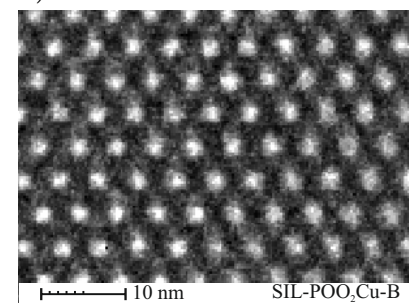

e)

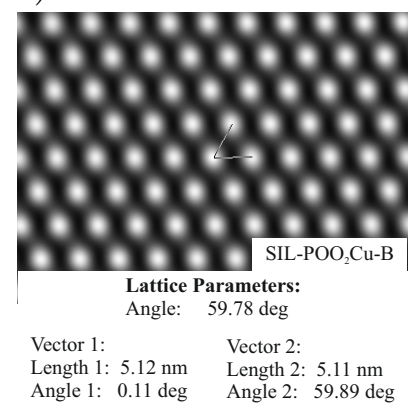

b)

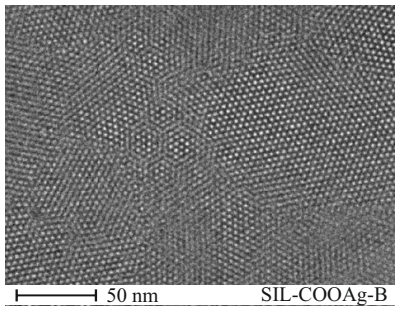

d)

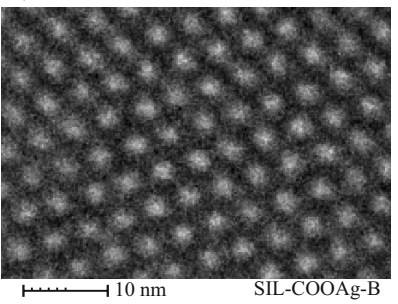

f)

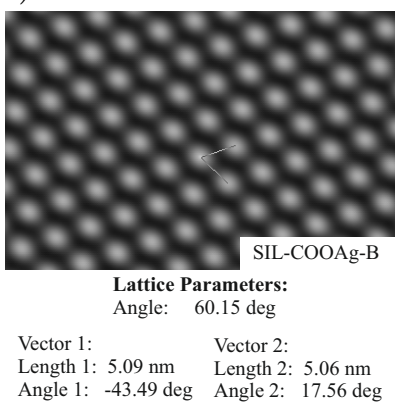

Figure 4: TEM images in various scales of porous silica thin films containing functional units at the pores bottom $(\mathrm{a}-\mathrm{d})$ along with with the results of $2 \mathrm{D}$ autocorrelation function and lattice parameters (e, f). Samples contain propyl-copper-phosphonate units (a, c, e) and propyl-silver-carbonatee $(b, d, f)$. 
a)

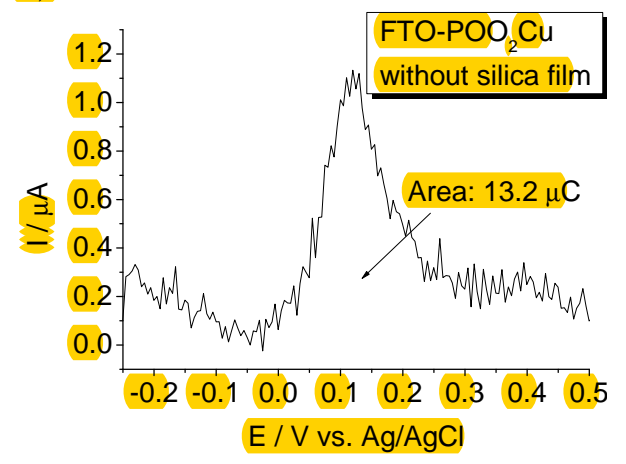

c)

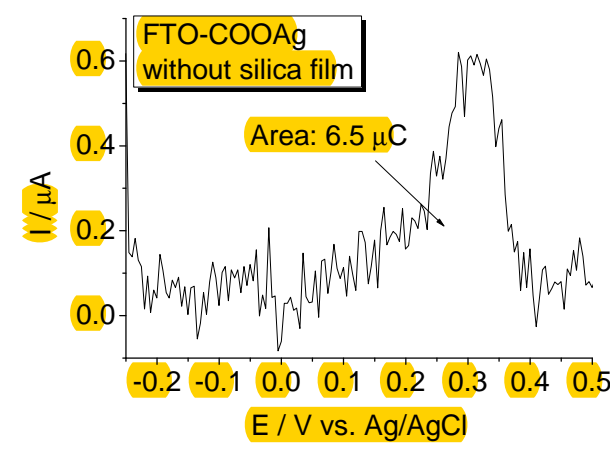

b)

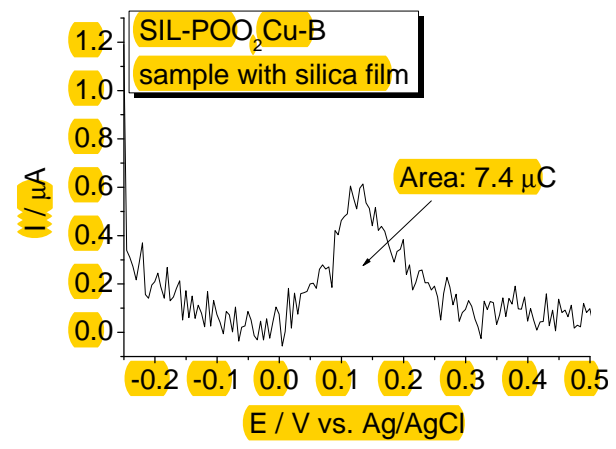

d)

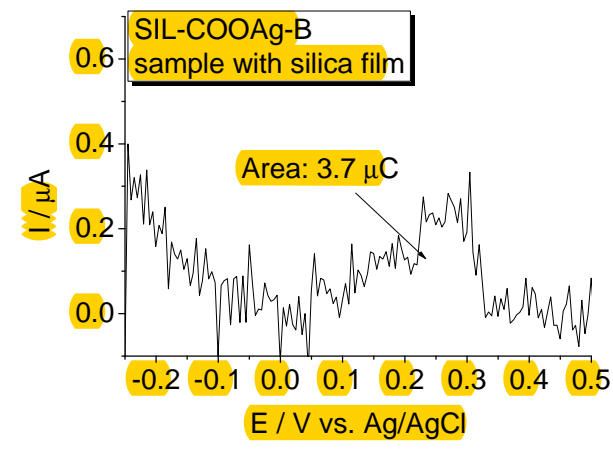

Figure 5: Differential pulse voltammetry (DPV) spectra recorded for metal-functionalized samples: FTO covered glass functionalized by propyl-copper-phosphonate (a), and propylsilver-carbonate (c) groups compared with spectra of glass-FTO covered with mesoporous silica thin film containing functional groups at the bottom: propyl-copper-phosphonate (b), and propyl-silver-carbonate (d). 
to ca. $56 \%$ of the values measured for bare FTO substrates activated by the metal ions (FTO-POO${ }_{2} \mathrm{Cu}$ and FTO-COOAg). This is consistent with the fact that vertically aligned silica films occupy about $50 \%$ of electrode's surface (on the basis of 75,000 pores $\mu \mathrm{m}^{-2}$ and $3 \mathrm{~nm}$ pore diameter [19], confirming that metal ions are anchored exclusively at the pores bottom. It is also worth to note that peak areas for silver-containing samples are about two times lower than for copper-functionalized samples, suggesting similar surface coverage for both complexes (on the basis of 2 electrons exchanged for copper detection and only 1 for silver). Finally, the presence of ligands and complexes at the bottom of pore channels does not affect the permeability of the mesoporous silica film, as pointed out by cyclic voltammetry using a redox probe in the solution (see part 2.1. in Supporting Information).

\subsection{Vibrational spectroscopy}

Finally, as a last point of our investigation, the molecular structure and configuration of the functional units were determined by the infrared spectroscopy supported by numerical simulations. We prepared three theoretical models reflecting arrangement of the functional units. They contain a fragment of the substrate that was prepared to illustrate its impact on vibrational modes. The structures for optimized molecules model shows fig. 6 .

For copper-containing samples, we expect only one conformation while for the silver-containing ones two conformations of the functional units should be possible (fig. 6). The numerical simulations enabled position determination of the characteristic bands (vibrational modes caused by functional units enabled molecular structure's identification). To better illustrate the dependences between therotical and experimental infrared data, the experimental spectra were deconvoluted using peak fitting analysis to find the position as well as the full width at half maximum (FWHM) of the main band. The juxtaposition of experimental and simulated spectra shows fig. 7 .

In both samples, we can observe vibrational modes connected with stretching and bending of functional units. For the SIL-POO${ }_{2} \mathrm{Cu}-\mathrm{B}$ material the bands are centered at about 1250 and $850 \mathrm{~cm}^{-1}$ what corresponds to the methylene bridges and phosphonate group as stretching of $\mathrm{P}=\mathrm{O}$ and $\left(\mathrm{POO}_{2}\right) \mathrm{Cu}$ bonds, respectively. The bands below $1200 \mathrm{~cm}^{-1}$ are ascribed to the Si-O silica network vibration and are less affected by the implementation of the active units. In turn, the SIL-COOAg-B sample shows characteristic bands at the region of $1400-1800 \mathrm{~cm}^{-} 1$. These vibrations can be assigned to the vibrational modes of the carboxyl moieties. Additionally, the number and 
a)

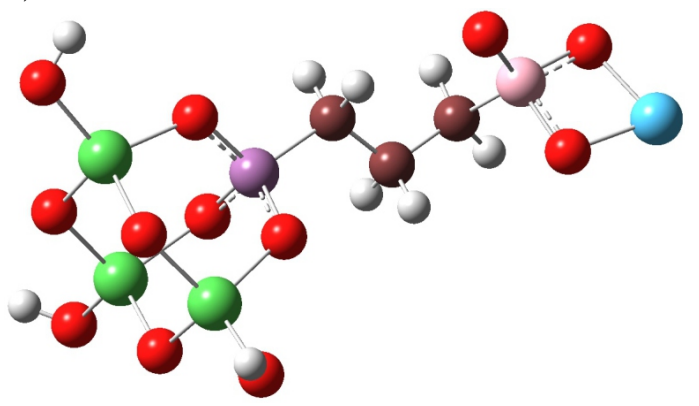

b)

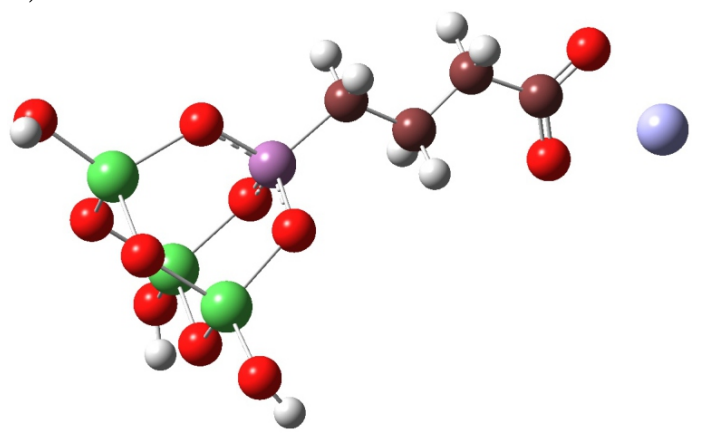

c)

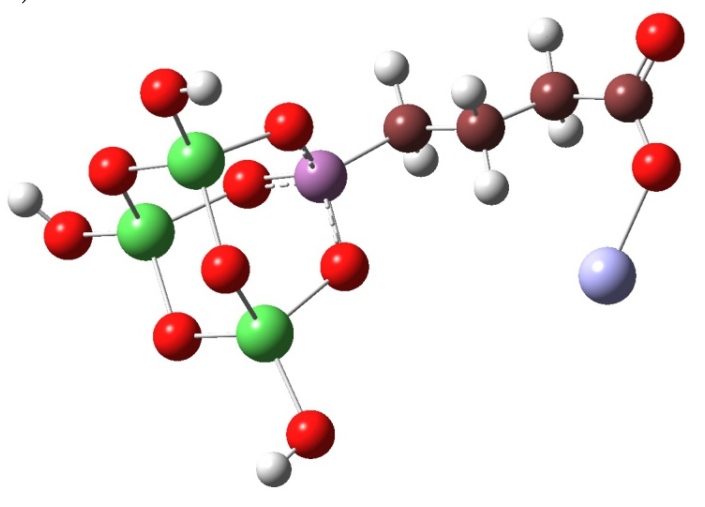

Legend:

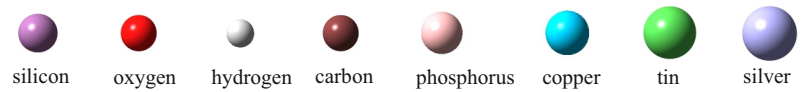

Figure 6: Numerical models of functional groups attached to tin dioxide fragment. Propylcopper-phosphonate group (a), propyl-silver-carbonate unit in first, strongly ionic conformation (b) and propyl-silver-carbonate unit in a second, more covalent conformation (c). 

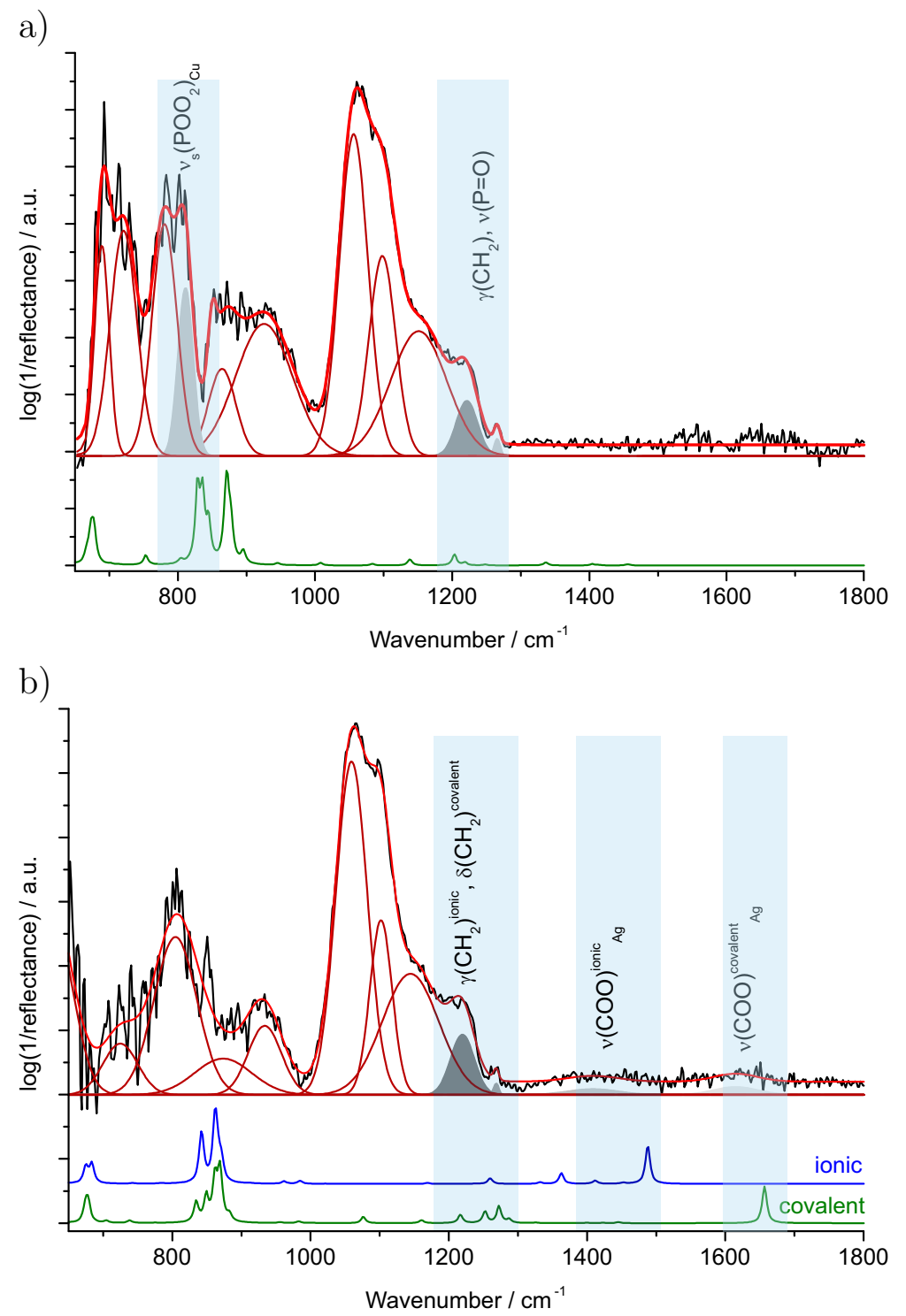

Figure 7: The juxtaposition of experimental infrared spectra obtained for porous thin silica layers containing copper (a) and silver (b) containing functional units at the bottom with theoretical spectra obtained for numerical models of this groups. For the case of silver containing units (b) two configurations of the functional groups are considered: ionic and covalent. Black line is an experimental result, brown lines represents deconvolution peeks, red line is a sum of deconvolution. Characteristic peeks were blue-highlighted. Symbols: $\nu$ - stretching modes, $\delta$ - in-plane bending (scissoring) 
position of the bands are strongly affected by the vicinity of the silver ion coordinating a carbonyl oxygen in a different way. The lower wavenumber band is ascribed to the ionic silver (see: fig. 6b) while the higher wavenumber-band is of covalent silver configuration in which the silver atom is bonded to one of the carbonyl oxygen (see: fig. 6c). On this base, we can conclude about the presence of two different configurations of the silver-containing functional units in this sample. Detailed analysis of the infrared spectroscopy supported by the numerical simulations is included in the Supporting Information, section 2.2 .

\section{Conclusion}

Concluding, we presented a novel method allowing for fabrication of precisely functionalized vertically aligned porous silica thin films that possess functional units anchored exclusively at the pores bottom. The effectiveness of method was proved on examples of the porous silica layers containing propyl copper phosphonate and propyl silver carbonate groups. We are confident that the described method can be easily generalized and applied for various functional units to create a novel functional nanomaterials family. We obtained silica films with high level or ordering, thus the ligand grafting and metal ions attachment do not disturb the growth of vertically aligned mesoporous films nor damage their structure. The presence of functional units at the pores bottom was confirmed directly via differential pulse voltammetry, while the functional units configuration was confirmed by means of the infrared spectroscopy supported by the numerical simulations. Thus we have unambiguously proven that the multistep functionalization method is an efficient way for precisely functionalized materials preparation. We are certain that described method can be easily generalized and applied to various functional units to create a novel functional nanomaterials family.

\section{Acknowledgements}

The authors are grateful to the National Centre of Science for financial support for this investigation (Grant-No: 2017/26/E/ST5/00162 and 2015/17/N/ST5/03328). The numerical simulations were supported by Poznan Supercomputer-Network Centre (grant id 305) and by PL-Grid Infrastructure. We are also grateful to ROOTINNOVATION ltd for support in numerical simulations. 


\section{References}

[1] R. Corriu, "Where organosilicon chemistry is going?," Journal of Organometallic Chemistry, vol. 686, p. 1, 2003.

[2] Q. Zhang and F. Saito, "A review on mechanochemical syntheses of functional materials," Advanced Powder Technology, vol. 23, no. 5, pp. 523 $-531,2012$.

[3] C. Hang, H.-W. Wu, and L.-L. Zhu, "Pi-conjugated cyanostilbene-based optoelectric functional materials," Chinese Chemical Letters, vol. 27, no. 8, pp. 1155 - 1165, 2016.

[4] S. Ameer, I. H. Gul, N. Mahmood, and M. Mujahid, "Semiconductor-tometallic flipping in a znfe2o4-graphene based smart nano-system: Temperature/microwave magneto-dielectric spectroscopy," Materials Characterization, vol. 99, pp. $254-265,2015$.

[5] X. Guo, B. Sun, D. Su, X. Liu, H. Liu, Y. Wang, and G. Wang, "Recent developments of aprotic lithium-oxygen batteries: Functional materials determine the electrochemical performance," Science Bulletin, pp. 442 $-452,2017$.

[6] E. Laukhina, V. Lebedev, V. Laukhin, A. P. del Pino, E. B. Lopes, A. I. Neves, D. Belo, M. Almeida, J. Veciana, and C. Rovira, "Polycarbonate films metalized with a single component molecular conductor suited to strain and stress sensing applications," Organic Electronics, vol. 13, no. 5, pp. $894-898,2012$.

[7] H. Jia, J. Cao, and Y. Lu, "Design and fabrication of functional hybrid materials for catalytic applications," Current Opinion in Green and Sustainable Chemistry, pp. -, 2017.

[8] X. Liu, M. Zhang, D. Yu, T. Li, M. Wan, H. Zhu, M. Du, and J. Yao, "Functional materials from nature: honeycomb-like carbon nanosheets derived from silk cocoon as excellent electrocatalysts for hydrogen evolution reaction," Electrochimica Acta, vol. 215, pp. 223 - 230, 2016.

[9] B. Xu, "Gels as functional nanomaterials for biology and medicine," Langmuir, vol. 25, no. 15, pp. 8375-8377, 2009. 
[10] M. Cavallari, G. Santos, and F. Fonseca, "2 - nanoelectronics," in Nanoscience and its Applications (A. L. D. RĂłz, M. Ferreira, F. d. L. Leite, and O. N. Oliveira, eds.), Micro and Nano Technologies, pp. $35-$ 69, William Andrew Publishing, 2017.

[11] L. Grzadziel, M. Krzywiecki, G. Genchev, and A. Erbe, "Effect of order and disorder on degradation processes of copper phthalocyanine nanolayers," Synthetic Metals, vol. 223, pp. 199 - 204, 2017.

[12] G. Brammertz, B. Vermang, H. ElAnzeery, S. Sahayaraj, S. Ranjbar, M. Meuris, and J. Poortmans, "Fabrication and characterization of ternary cu8sis6 and cu8sise6 thin film layers for optoelectronic applications," Thin Solid Films, vol. 616, pp. 649 - 654, 2016.

[13] M. Zarchi and S. Ahangarani, "The role of operations after the deposition on the performance of siox films in optoelectronics devices," Optical Materials, vol. 46, pp. 223 - 227, 2015.

[14] M. Hala, H. Kato, M. Algasinger, Y. Inoue, G. Rey, F. Werner, C. Schubbert, T. Dalibor, and S. Siebentritt, "Improved environmental stability of highly conductive nominally undoped zno layers suitable for n-type windows in thin film solar cells," Solar Energy Materials and Solar Cells, vol. 161, pp. $232-239,2017$.

[15] C. Macdzias, S. Lugo, A. Benidztez, I. Lopez, B. Kharissov, A. Vazquez, and Y. Pena, "Thin film solar cell based on cusbs2 absorber prepared by chemical bath deposition (cbd)," Materials Research Bulletin, vol. 87, pp. $161-166,2017$.

[16] F. Terenziani and A. Painelli, "Supramolecular interactions in clusters of polar and polarizable molecules," Physical Review B, vol. 68, no. 16, p. 165405, 2003.

[17] L. Laskowski, M. Laskowska, K. Fijalkowski, H. Piech, J. Jelonkiewicz, M. Jaskulak, A. Gnatowski, and M. Dulski, "New class of antimicrobial agents: Sba-15 silica containing anchored copper ions," Journal of Nanomaterials, vol. 2017, p. 1287698, 2017.

[18] M. Laskowska, I. Kityk, M. Dulski, J. Jedryka, A. Wojciechowski, J. Jelonkiewicz, M. Wojtyniak, and L. Laskowski, "Functionalized 
mesoporous silica thin films as a tunable nonlinear optical material," Nanoscale, vol. 9, no. 33, pp. 12110-12123, 2017.

[19] A. Walcarius, E. Sibottier, M. Etienne, and J. Ghanbaja, "Electrochemically assisted self-assembly of mesoporous silica thin films," Nature materials, vol. 6, no. 8, pp. 602-608, 2007.

[20] N. Vilà, J. Ghanbaja, E. Aubert, and A. Walcarius, "Electrochemically assisted generation of highly ordered azide-functionalized mesoporous silica for oriented hybrid films," Angewandte Chemie International Edition, vol. 53, no. 11, pp. 2945-2950, 2014.

[21] D. Nedzas and P. Klapetek, "Gwyddion: an open-source software for SPM data analysis," Central European Journal of Physics, vol. 10, pp. 181-188, 2012.

[22] C.-Y. Kim and D.-H. Riu, "Raman scattering, electrical and optical properties of fluorine-doped tin oxide thin films with (200) and (301) preferred orientation," Materials Chemistry and Physics, vol. 148, no. 3, pp. 810-817, 2014.

[23] L. Radom, P. R. Schleyer, J. Pople, and W. Hehre, "Ab initio molecular orbital theory," 1986.

[24] R. G. Parr, "Density functional theory of atoms and molecules," in Horizons of Quantum Chemistry, pp. 5-15, Springer, 1980.

[25] M. J. Frisch, G. W. Trucks, H. B. Schlegel, G. E. Scuseria, M. A. Robb, J. R. Cheeseman, G. Scalmani, V. Barone, B. Mennucci, G. A. Petersson, H. Nakatsuji, M. Caricato, X. Li, H. P. Hratchian, A. F. Izmaylov, J. Bloino, G. Zheng, J. L. Sonnenberg, M. Hada, M. Ehara, K. Toyota, R. Fukuda, J. Hasegawa, M. Ishida, T. Nakajima, Y. Honda, O. Kitao, H. Nakai, T. Vreven, J. A. Montgomery, Jr., J. E. Peralta, F. Ogliaro, M. Bearpark, J. J. Heyd, E. Brothers, K. N. Kudin, V. N. Staroverov, R. Kobayashi, J. Normand, K. Raghavachari, A. Rendell, J. C. Burant, S. S. Iyengar, J. Tomasi, M. Cossi, N. Rega, J. M. Millam, M. Klene, J. E. Knox, J. B. Cross, V. Bakken, C. Adamo, J. Jaramillo, R. Gomperts, R. E. Stratmann, O. Yazyev, A. J. Austin, R. Cammi, C. Pomelli, J. W. Ochterski, R. L. Martin, K. Morokuma, V. G. Zakrzewski, G. A. Voth, P. Salvador, J. J. Dannenberg, S. Dapprich, A. D. 
Daniels, . Farkas, J. B. Foresman, J. V. Ortiz, J. Cioslowski, and D. J. Fox, "Gaussian09." Gaussian Inc. Wallingford CT 2009.

[26] A. D. Becke, "Density-functional exchange-energy approximation with correct asymptotic behavior," Physical review A, vol. 38, no. 6, p. 3098, 1988.

[27] A. D. Becke, "Density-functional thermochemistry. iii. the role of exact exchange," The Journal of chemical physics, vol. 98, no. 7, pp. 56485652, 1993.

[28] T. Yanai, D. P. Tew, and N. C. Handy, "A new hybrid exchangecorrelation functional using the coulomb-attenuating method (camb3lyp)," Chemical Physics Letters, vol. 393, no. 1, pp. 51-57, 2004.

[29] C. Lee, W. Yang, and R. G. Parr, "Development of the colle-salvetti correlation-energy formula into a functional of the electron density," Physical review B, vol. 37, no. 2, p. 785, 1988.

[30] F. Weigend and R. Ahlrichs, "Balanced basis sets of split valence, triple zeta valence and quadruple zeta valence quality for $\mathrm{h}$ to $\mathrm{rn}$ : Design and assessment of accuracy," Physical Chemistry Chemical Physics, vol. 7, no. 18, pp. 3297-3305, 2005.

[31] F. Weigend, "Accurate coulomb-fitting basis sets for h to rn," Physical chemistry chemical physics, vol. 8, no. 9, pp. 1057-1065, 2006.

[32] M. K. Kesharwani, B. Brauer, and J. M. Martin, "Frequency and zero-point vibrational energy scale factors for double-hybrid density functionals (and other selected methods): can anharmonic force fields be avoided?" The Journal of Physical Chemistry A, vol. 119, no. 9, pp. 1701-1714, 2014.

[33] M. H. Jamroz, J. Dobrowolski, and R. Brzozowski, "Vibrational modes of 2,6-, 2,7-, and 2,3-diisopropylnaphthalene. a DFT study," Journal of Molecular Structure, vol. 787, no. 1-3, pp. 172 - 183, 2006.

[34] M. Vakili, S. F. Tayyari, M. Hakimi-Tabar, A.-R. Nekoei, and S. Kadkhodaei, "Structure and vibrational assignment of bis(benzoylacetonato)copper(ii)," Journal of Molecular Structure, vol. 1058, no. 0, pp. $308-317,2014$. 
[35] R. Dennington, T. Keith, and J. Millam, "Gaussview Version 5." Semichem Inc. Shawnee Mission KS 2009.

[36] M. Jamroz, "Vibrational energy distribution analysis (VEDA): Scopes and limitations," Spectrochimica Acta Part A: Molecular and Biomolecular Spectroscopy, vol. 114, p. 220ď̀"230, 2013.

[37] E. Laborda, J. González, and Á. Molina, "Recent advances on the theory of pulse techniques: A mini review," Electrochemistry Communications, vol. 43, pp. 25-30, 2014.

[38] M. Etienne, J. Bessiere, and A. Walcarius, "Voltammetric detection of copper (ii) at a carbon paste electrode containing an organically modified silica," Sensors and Actuators B: Chemical, vol. 76, no. 1-3, pp. 531-538, 2001. 